\title{
Urinary Excretion of Immunoreactive Luteinizing Hormone-Releasing Hormone-Like Material and Gonadotropins at Different Stages of Life*
}

\author{
JEAN-PIERRE BOURGUIGNON, CLAIRE HOYOUX, AIMEE REUTER, AND PAUL \\ FRANCHIMONT, WITH THE ASSISTANCE OF COLETTE LEINARTZ-DOURCY AND \\ YVONNE VRINDTS-GEVAERT \\ Clinique Pédiatrique, Université de Liège, Hôpital de Bavière, and the Department of Internal Medicine, \\ Tour de Pathologie, CHU, Bâtiment B23, Sart-Tilman, Liège, Belgium
}

\begin{abstract}
LHRH-like immunoreactivity (IR LHRH) excreted in human urine spontaneously or after iv injection of LHRH was studied. It was characterized by gel filtration on carboxymethyl-cellulose and RIA using two antisera with different affinities for LHRH fragments. From these studies, it was suggested that the material excreted after iv injection of 1-10 LHRH was heterogeneous and contained at least 1-10 and 2-10 LHRH. In contrast the properties of endogenous urinary material were consistent with the absence of detectable intact decapeptide and the presence of 2-10 nonapeptide of LHRH as a major excretory product.

In 24-h urines obtained from 292 normal subjects, IR LHRH FSH, and LH were assayed and related to their chronological
\end{abstract}

ages. The mean level of IR LHRH was found to be the lowest in male and female infants ( 3.2 and $2.9 \mathrm{ng} / 24 \mathrm{~h}$ ), and to rise gradually in prepubertal boys and girls until $11 \mathrm{yr}$ and markedly in postmenopausal women ( $49 \mathrm{ng} / 24 \mathrm{~h}$ ). No significant differences of urinary IR LHRH excretion appeared between the last prepubertal aged subject and pubertal or adult subjects. A significant positive correlation between urinary IR LHRH and both FSH and LH was observed in prepubertal boys and girls, in pubertal boys, and (for LH only) in adult males. No correlation was observed in infants of either sex or in pubertal, adult, or postmenopausal females. ( $J$ Clin Endocrinol Metab 48: 78, 1979)
$\mathrm{S}^{\mathrm{n}}$ INCE LHRH has been found to be excreted in urine (1-4), several authors attempted to characterize and assay immunoreactive LHRH (IR LHRH) in this biological fluid. Results obtained were in disagreement on several points: 1) several different peptides derived from LHRH were characterized in the urinary immunoreactive material $(2,5-8)$; and 2$)$ the amounts detected by RIA varied widely even when the same antiserum (R42, provided by Drs. Nett and Niswender) was utilized. Using this anti-LHRH antibody, we had previously found detectable immunoreactivity in urine, suggesting the possible presence of $1-10$ or $2-10$ LHRH (8). Using two different antisera, complementary studies of the material excreted in urine spontaneously or after iv injection were undertaken. The aim of this work was: 1) to further characterize immunological and physicochemical properties of urinary IR LHRH; 2) to apply its assay to

Received November 28, 1977.

Address requests for reprints to: Dr. J. P. Bourguignon, Clinique Pédiatrique, Hôpital de Bavière, 4020 Liège, Belgium.

* Presented in part at the $16^{\text {th }}$ Meeting of the European Society for Pediatric Endocrinology, Cambridge, U.K., September, 1977. normal males and females at different ages; and 3) to investigate its connection with gonadotropins excreted in urine.

\section{Materials and Methods}

\section{Subjects}

In 129 normal females, (aged 12 weeks to $88 \mathrm{yr}$ ) and 163 normal males (aged 2 weeks to $54 \mathrm{yr}$ ), 24-h urines were collected and stored at $-20 \mathrm{C}$ until assayed. Furthermore, the prepubertal period was particularly studied using 24 -h urines obtained from 174 boys and girls aged 3-10 yr. The subjects were distributed in several groups according to their sex and chronological age. The 11- to 15-yr-old group contained children at different stages of pubertal maturation. The adult women were normally menstruated and at different phases of the cycle.

\section{Extraction of LHRH-like material from urine}

The extraction procedure has been previously described ( 8 , 9). LHRH-like material was extracted from $1 \mathrm{ml}$ urine adjusted to $\mathrm{pH}$ 6.8-7.2 using adsorption on $200 \mathrm{mg}$ porous glass (Spherosil, Rhōne-Poulenc) and recovered by agitation in $3 \mathrm{ml}$ methanol acidified to $\mathrm{pH} 3$ by acetic acid. After centrifugation at 
$10,000 \times g$ for $10 \mathrm{~min}$, the supernatant was separated and evaporated to dryness. The extracts were dissolved in $0.2 \mathrm{ml}$ phosphate-buffered saline enriched with blue bromothymol to ensure the neutrality of the solution by colorimetry. The yield was found to be $80 \%$ using labeled LHRH and around $70 \%$ using unlabeled LHRH. The percentages of adsorption on Spherosil and recovery by methanol were constant and irrespective of the amounts of synthetic LHRH used. When submitted to this extraction procedure, radioiodinated LHRH retained a similar percentage of binding to the antibody.

The yield was not modified when synthetic LHRH was extracted in urine enriched with various concentrations of albumin $(0.001-0.5 \mathrm{mg} / \mathrm{ml})$. The salt content of the extract was not significantly different from that of the solubilizing buffer. The reproducibility was studied by extraction in duplicate of 100 different urine samples and subsequent RIA of LHRH. The correlation coefficient between results obtained after the duplicate extractions was 0.89 and the variation coefficient was $15.1 \%$.

\section{Urinary LHRH-like material RIA}

The assay was performed using a single antibody method with separation of the free labeled hormone by fixation on uncoated charcoal $(10,11)$.

Two different anti-LHRH antisera were used. Antiserum I, used at a final dilution of $1 / 200,000$, was a generous gift of Drs. Nett and Niswender. The high specificity of this antiserum for both $\mathrm{C}$ - and $\mathrm{N}$-terminal extremities of the decapeptide has been previously shown (12). However, cross-reactions with the 2-10 nonapeptide of LHRH (2.6\% and $3.8 \%)$ were respectively reported by Jonas et al. (13) and Dahlen et al. (14). In our assay conditions (Table 1), antiserum I showed on a molar basis $3.03 \%$ cross-reaction with 2-10 LHRH and less than $0.01 \%$ with other fragments. Antiserum II, prepared by Burger and Franchimont (11), was used at a final dilution of $1 / 100,000$. It cross-reacted with C-terminal fragments (Table 1) and particularly with the 2-10 nonapeptide (29.9\%).

In the presence of $\mathrm{N}$-terminal fragments with less than seven residues, no significant cross-reaction was observed. This specificity for the C-terminus was assessed by the substitution of that residue with ethylamide, resulting in a fall of the crossreactivity below $0.01 \%$.

The limit of sensitivity was $0.5-1 \mathrm{pg} /$ tube or $/ 1 \mathrm{ml}$ urine using antiserum I, and 1-2 pg using antiserum II. Using both

TABLE 1. Specificity of two different anti-LHRH antisera: percentage of cross-reactivity (molar basis) with LHRH fragments or analog

\begin{tabular}{|c|c|c|c|}
\hline \multicolumn{2}{|c|}{ Peptide } & \multicolumn{2}{|c|}{ Anti-LHRH } \\
\hline Structure & $\begin{array}{l}\text { Amino acids of } \\
\text { LHRH }\end{array}$ & I & II \\
\hline$p \mathrm{Glu} \rightarrow \mathrm{Gly}-\mathrm{NH}_{2}$ & $1 \rightarrow 10$ & 100 & 100 \\
\hline $\mathrm{His} \rightarrow \mathrm{Gly}-\mathrm{NH}_{2}$ & $2 \rightarrow 10$ & 3.03 & 29.9 \\
\hline $\operatorname{Trp} \rightarrow$ Gly-NH $\mathrm{NH}_{2}$ & $3 \rightarrow 10$ & $<0.01$ & 4.75 \\
\hline $\mathrm{Arg} \rightarrow$ Gly $-\mathrm{NH}_{2}$ & $8 \rightarrow 10$ & $<0.01$ & $<0.01$ \\
\hline Ethylamide ${ }^{10}$ & $1 \rightarrow$ 9-Ethyl. & & $<0.01$ \\
\hline$p$ Glu $\rightarrow$ Gly & $1 \rightarrow 6$ & $<0.01$ & $<0.01$ \\
\hline$p$ Glu $\rightarrow$ Leu & $1 \rightarrow 7$ & $<0.01$ & \\
\hline
\end{tabular}

antisera, the within- and interassay precision defined by the coefficient of variation varied respectively from $5-10 \%$ and from $13-18 \%$.

The daily variations were studied to determine the biological variability of IR LHRH excretion in urine. In 14 subjects, 24-h urines were collected for 3-5 different days and the amount of IR LHRH was assayed; the mean coefficient of variation was found to be $32 \%$.

\section{Urinary gonadotropin RIAs}

Urinary gonadotropins were quantified by RIA of $100 \mu$ l unextracted urine in duplicate. The techniques were previously described $(15,16)$. The reference preparation was MRC 67/161 2nd HMG. Inhibition curves, obtained with several dilutions of unextracted urine from menopausal women, were parallel to the standard curve. The sensitivity was $10-25 \mathrm{pg} /$ tube for both FSH and LH. For comparisons between different age groups, the values which fell within the limits of assay sensitivity were used.

\section{Validation of the assay of urinary IR LHRH}

Characterization studies of urinary IR LHRH were performed by gel filtration of different materials on carboxymethylcellulose (CM-cellulose). Column and buffer conditions were those previously reported by Jeffcoate and Holland (5). The studied materials were of both synthetic and biological origin; synthetic peptides were 1-10 and 2-10 LHRH dissolved and eluted in the column buffer.

The elution of 1-10 LHRH was repeated after previous incubation at $4 \mathrm{C}$ for $24 \mathrm{~h}$ in a $1-\mathrm{ml}$ sample of urine concentrated 10-fold. Biological materials were rat hypothalami and human urine. Rat hypothalamic extracts were obtained by homogenization in $2 \mathrm{~N}$ acetic acid at $4 \mathrm{C}$, centrifugation at $10,000 \times \mathrm{g}$ for $30 \mathrm{~min}$, and neutralization of the supernatant by ammonium hydroxide. Two kinds of urinary materials were studied: $2 \mathrm{ml}$ unextracted urine collected at $30 \mathrm{~min}$ after the iv injection of 10 $\mu \mathrm{g}$ 1-10 LHRH/kg BW into one man (17), and a 1-ml sample of the extract of $200 \mathrm{ml}$ urine obtained from a menopausal woman. Urine obtained after iv injection of $\mathrm{LHRH}$ was lyophilized and dissolved in $1 \mathrm{ml}$ column buffer. The eluted fractions were comparatively assayed with anti-LHRH I and II.

Finally, in several dilutions of the same urinary extract, IR LHRH was determined with both antisera. From those values, the mean quantity of immunoreactive material ( \pm SD) was calculated in both anti-LHRH assay systems.

\section{Statistical studies}

The linear correlation between urinary gonadotropins and IR LHRH was calculated. The significance of $r$ (correlation coefficient) and comparisons between the different groups were calculated using Student's unpaired $t$ test.

\section{Results}

\section{Characterization of urinary IR LHRH}

CM-Cellulose allowed a clear separation between synthetic 1-10 and 2-10 LHRH (Fig. 1), in accordance with 


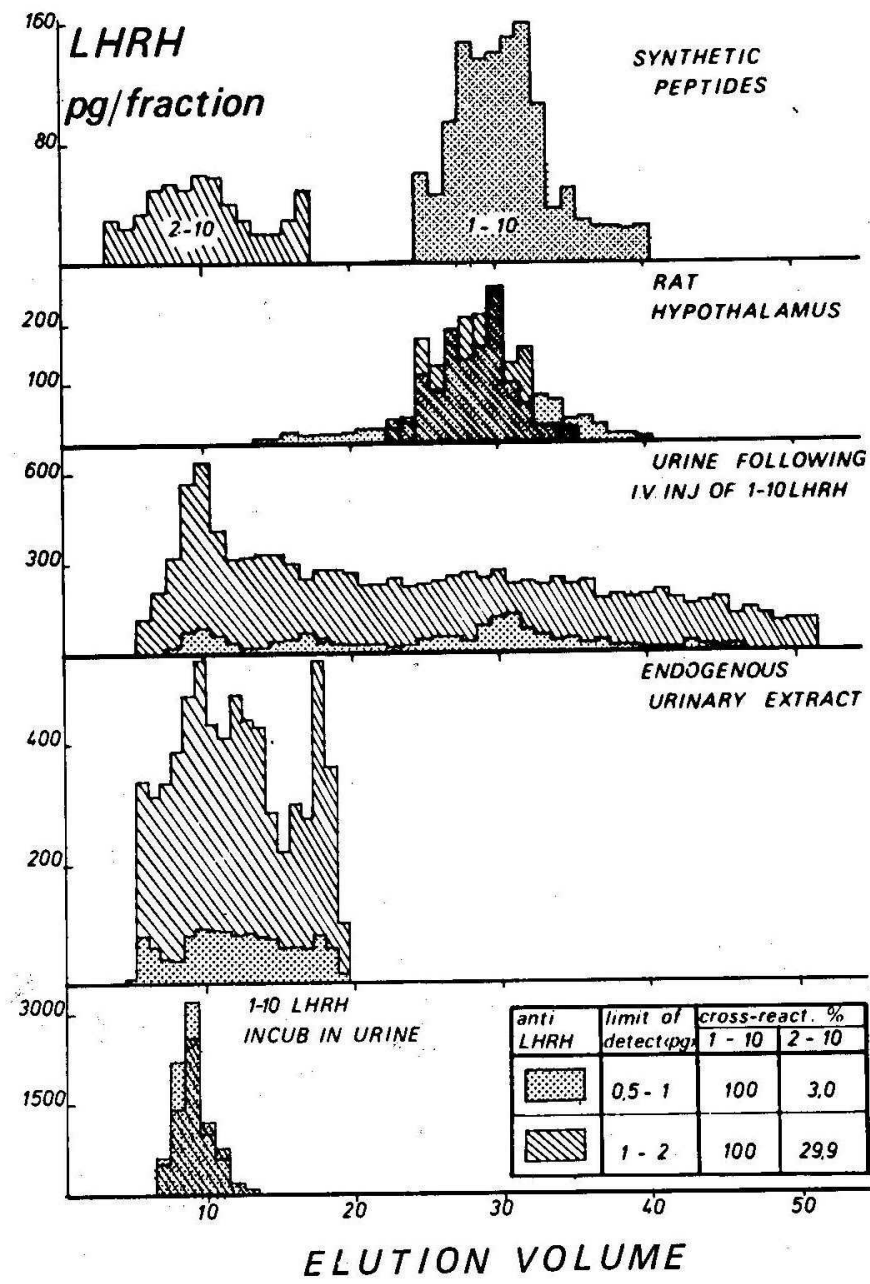

Fig. 1. Elution pattern of LHRH-like immunoreactivity from chromatography of different synthetic and biological materials on CMcellulose. The fractions collected $(1 \mathrm{ml})$ were assayed using two antiLHRH antisera: no. I, 중; and no. II,

Jeffcoate and Holland (5). Rat hypothalamic extracts showed an elution volume identical to that of the decapeptide, and the quantity of immunoreactive material detected by both antisera was similar (Fig. 1). Urinary material showed a major peak of 2-10 nonapeptide-like material after 1-10 LHRH iv injection in a normal male and in the urinary extract from a menopausal female (Fig. 1). Furthermore, in all the fractions eluted from both urinary materials, a greater amount of immunoreactivity was found using antiserum II, which crossreacts more with the 2-10 nonapeptide than antiserum $I$.

A difference between the two urinary materials appeared at the 1-10 decapeptide position. No immunoreactivity was detected at this position in the effluent aliquots from endogenous urinary extract. In contrast, studying the material excreted after 1-10 LHRH injection, a significant amount of immunoreactivity was eluted at the 1-10 LHRH position. Moreover, the major peak of this material assayed using antiserum I was concomitant with 1-10 LHRH, suggesting the presence of intact decapeptide. This urinary material thus appeared to be heterogeneous and was likely to contain at least 1-10 and 2-10 LHRH moieties. After incubation in concentrated urine, 1-10 LHRH showed a changed mobility on CMcellulose and apparently behaved as the 2-10 nonapeptide, but the amounts of immunoreactivity assayed with both anti-LHRH antisera were similar.

Finally, an immunological parallelism between standard decapeptide and urinary extract was observed in both assay systems (Fig. 2). The amounts of IR LHRH (mean $\pm \mathrm{SD}$ ), calculated in terms of decapeptide from the standard curves, were $44.9 \pm 7.4 \mathrm{pg}$ with antiserum I and $312 \pm 42 \mathrm{pg}$ with antiserum II; thus, IR LHRH assayed in urinary extract appeared around 7 times greater with the latter than with the former.

\section{IR LHRH in 24-h urines of normal subjects (Fig. 3)}

The amount of immunoreactivity was determined using antiserum II. The mean excretion of LHRH-like material (nanograms per $24 \mathrm{~h}$ ) was the lowest in infants aged 2 weeks to 6 months (mean \pm sEM: boys, $3.38 \pm$ 0.21 ; girls, $2.87 \pm 0.61$ ). It is of note that only a few girls of this age were studied because of the difficulty in

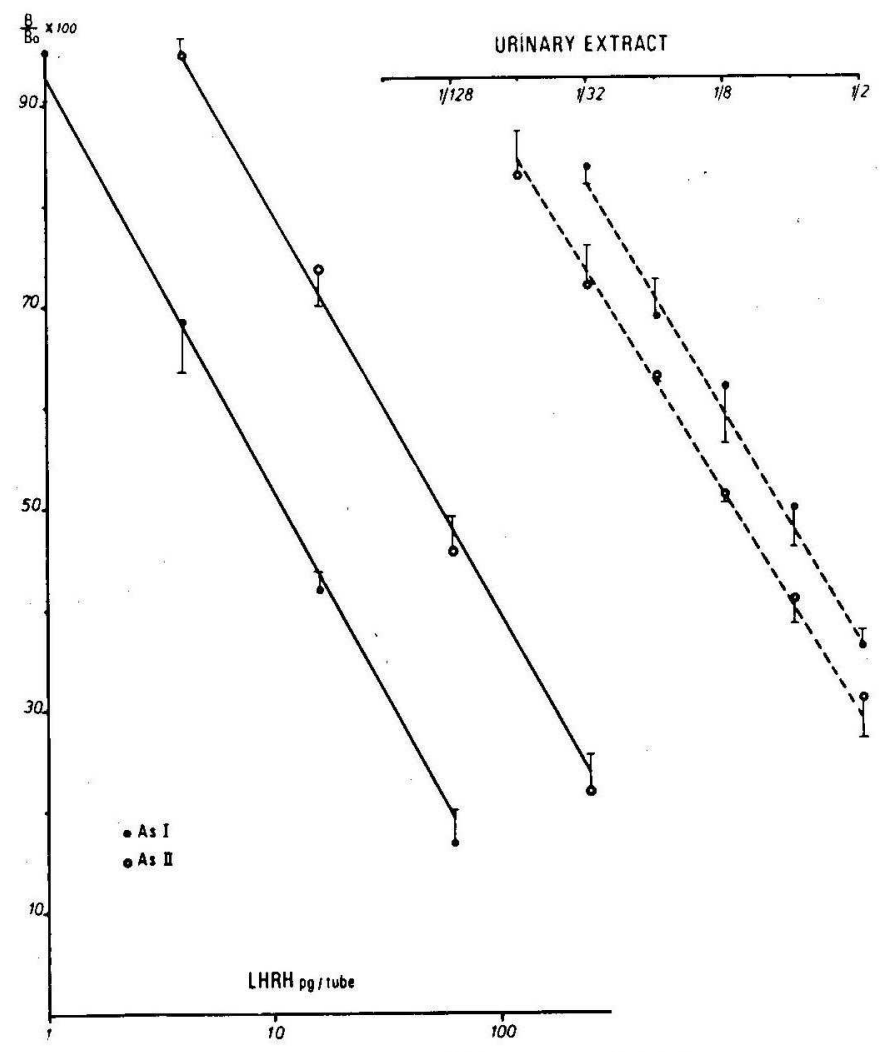

FIG. 2. Using two different anti-LHRH antisera, inhibition curves were obtained from several dilutions (logarithmic scale) of standard 1-10 LHRH ( $(-)$ and urinary extract (-- ). Each value was assayed in triplicate and $1 \mathrm{SD}$ is represented. 


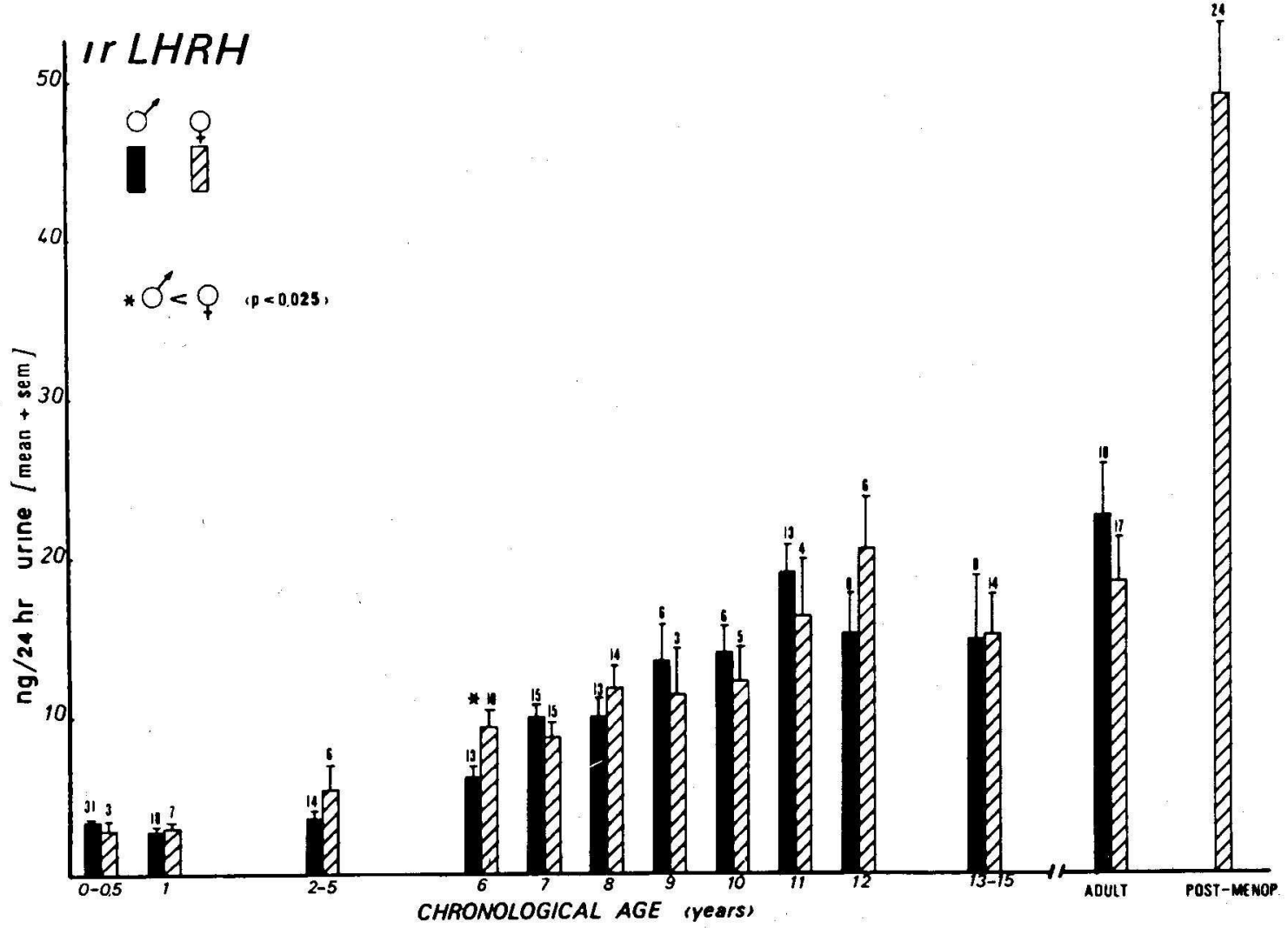

FIG. 3. Mean excretion of IR LHRH (+SEM) in urine compared in different age groups of males and females. The group aged less than 6 months do not contain neonates before 2 weeks of age.

collecting 24-h urines. The excretion of IR LHRH was similar in children aged 7-18 months and did not increase significantly until the age of $4 \mathrm{yr}$. From $4 \mathrm{yr}$ onward, a progressive rise was seen until the age of 10 . The levels observed in pubertal and adult subjects were not significantly different from those found at $10 \mathrm{yr}$ (Fig. 3). Finally, a striking increase was found in postmenopausal women (mean \pm SEM, $49 \pm 4.5$ ).

Significant differences between males and females were never found, except at $6 \mathrm{yr}$ where the values were significantly higher in girls than in boys when expressed in nanograms per 24-h urines.

Body size and, consequently, urine volume and the excretion of creatinine increase during childhood. For that reason, the increments of urinary hormones found in prepubertal children were related to the increases of urinary creatinine excreted per $24 \mathrm{~h}$ and expressed in nanograms per $1 \mathrm{~g}$ creatinine. The values of urinary hormones found in prepubertal children were compared when expressed per $24 \mathrm{~h}$ or normalized for the excretion of creatinine (Fig. 4). As no significant differences appeared between boys and girls, the values of both sexes were plotted together (except for IR LHRH excreted in boys of $6 \mathrm{yr}$ ) and expressed per $24 \mathrm{~h}$. Boys and girls of 6 yr were assembled to analyze the significance of the increments found in the other prepubertal children.

The mean excretion of IR LHRH, LH, and FSH in 24- $\mathrm{h}$ urine was found significantly increased in late prepubertal children (9 and $10 \mathrm{yr}$ ). When these values were normalized for the creatinine excretion, only a significant increase of IR LHRH appeared at 9 and $10 \mathrm{yr}$. This observation suggested that the prepubertal variation of urinary LHRH was not merely a reflection of growth.

\section{Urinary excretion of gonadotropins and correlation to IR $\mathrm{LHRH}$}

Individual values of FSH, LH, and IR LHRH in 24-h urine samples of males and females are shown on Figs. 5 and 6. In boys, as in girls, 24-h urinary FSH remained low until $8 \mathrm{yr}$ and was not significantly different from the values found in infants. In contrast, with regard to infants, a significant increase of mean LH excretion in 24$\mathrm{h}$ urine was observed in the 6-yr group in girls $(P<$ $0.001)$, and in the 2 - to 5 -yr-old group in boys $(P<0.01)$.

The linear correlation between urinary gonadotropins and IR LHRH was calculated (Table 2). A significant positive correlation with IR LHRH was found for both FSH and LH in prepubertal boys and girls and in pubertal boys and for LH only in adult males. No significant correlation was found in the other age groups.

\section{Discussion}

In this study, urinary LHRH-like immunoreactivity 


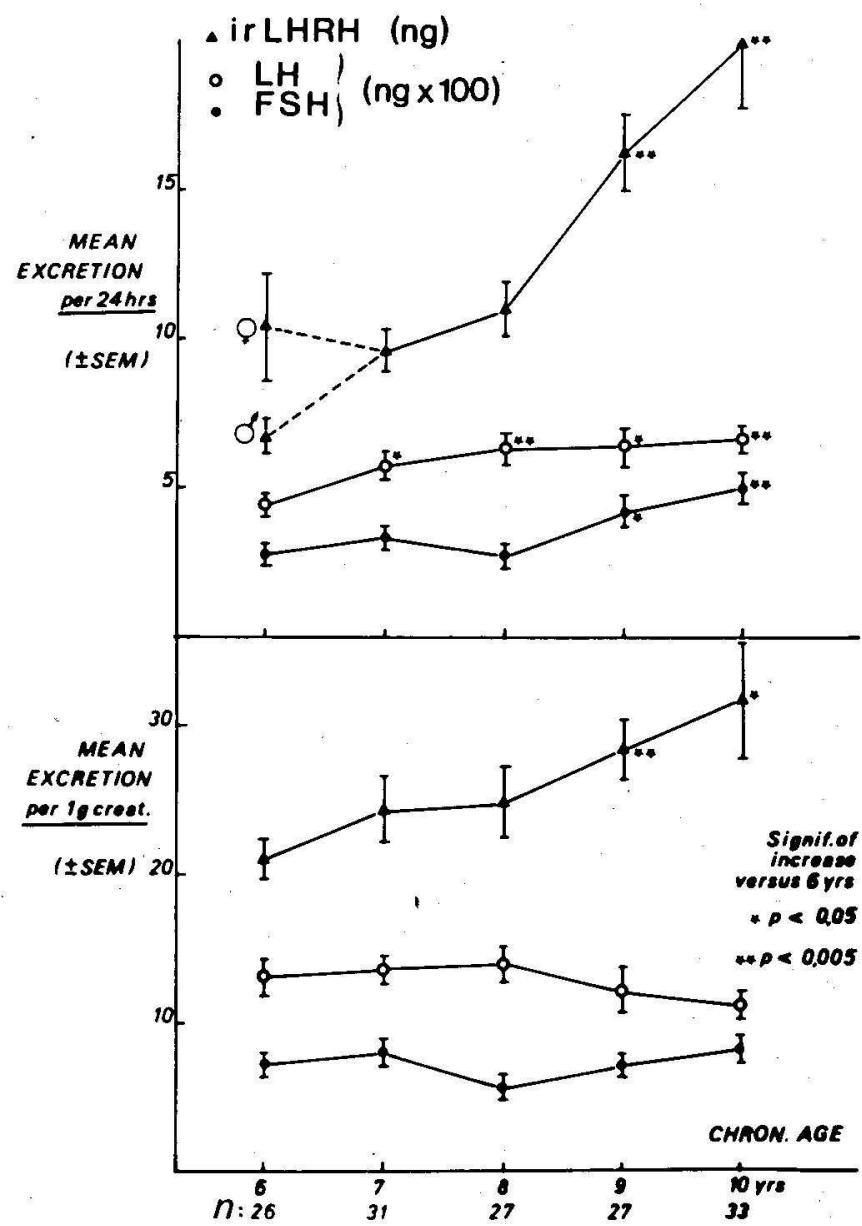

Fig 4. Mean excretion ( \pm SEM) of IR LHRH, LH, and FSH in 24-h urine of prepubertal children (6-10 yr). The prepubertal variations of these urinary hormones were compared when expressed per $24 \mathrm{~h}$ ( upper part) or per $1 \mathrm{~g}$ creatinine (lower part).

was characterized by its mobility on CM-cellulose gel column chromatography and its affinity to two different antisera. The previous findings of a chromatographical similarity between urinary radioactive (1) or IR (5) LHRH-like material and the 2-10 nonapeptide of LHRH were thus confirmed and supported by immunological studies. The material excreted in urine after iv injection of LHRH in a man was studied; from its elution pattern on CM-cellulose and its immunoreactivity using two antisera, this material appeared heterogeneous and contained at least 1-10 and 2-10 LHRH-like peptides.

On the other hand, the endogenous immunoreactivity of urine extracts was studied; this material showed physicochemical and immunological properties consistent with the presence of 2-10 LHRH as a major excretory product and the absence of detectable 1-10 LHRH. Thus, the immunoreactive substance assayed in urine using highly specific Niswender antiserum seemed to be different from the decapeptide and was assumed to arise from the slight cross-reaction of that antiserum with the 2-10 nonapeptide. This cross-reaction, although not reported in the study of Nett et al. (12), was previously described and found to be around $3 \%$ by Jonas et al. (13) and Dahlen et al. (14). These variations could be in keeping with the use of different pools of antiserum. Intact decapeptide thus seemed to be undetectable in endogenous urinary material, but this observation requires further confirmation using a highly sensitive bioassay, such as pituitary cells in monolayer cultures. Moreover, the possible presence of other metabolites of LHRH in urine was not excluded. Since endogenous LHRH has been characterized in human serum as chromatographically similar to the decapeptide (18), renal metabolism presumably leads to its conversion into derived peptides and especially the 2-10 nonapeptide.

An immunological parallelism was observed between urinary IR LHRH and the standard decapeptide, even in an anti-LHRH system cross-reacting with the derived oligopeptides. This emphasizes the limits of significance of such parallelism in the identification of related peptides.
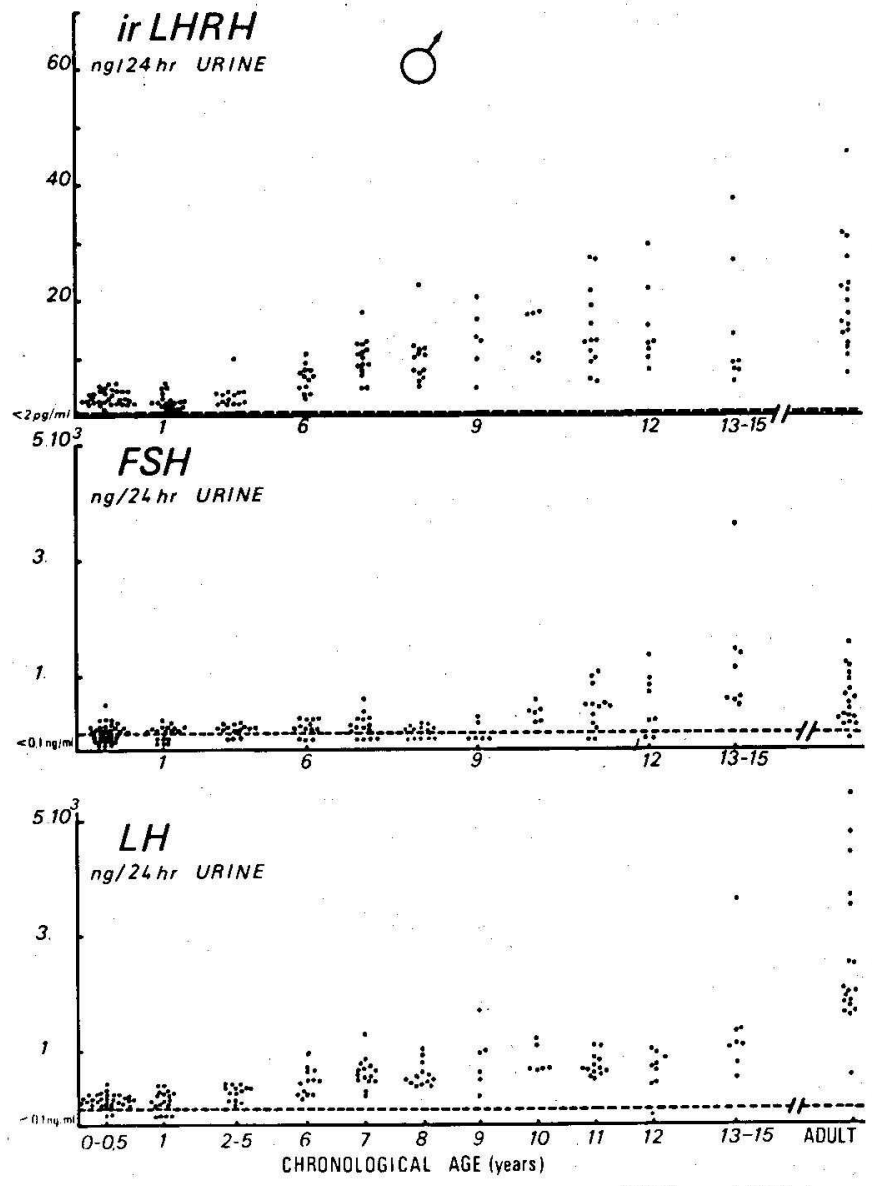

Fig. 5. Individual values of urinary IR LHRH, FSH, and LH (nanograms per $24 \mathrm{~h}$ ) were referred to the chronological ages of normal males. Values plotted under the dotted lines were below the limit of assay sensitivity. The youngest boy was aged 2 weeks. 

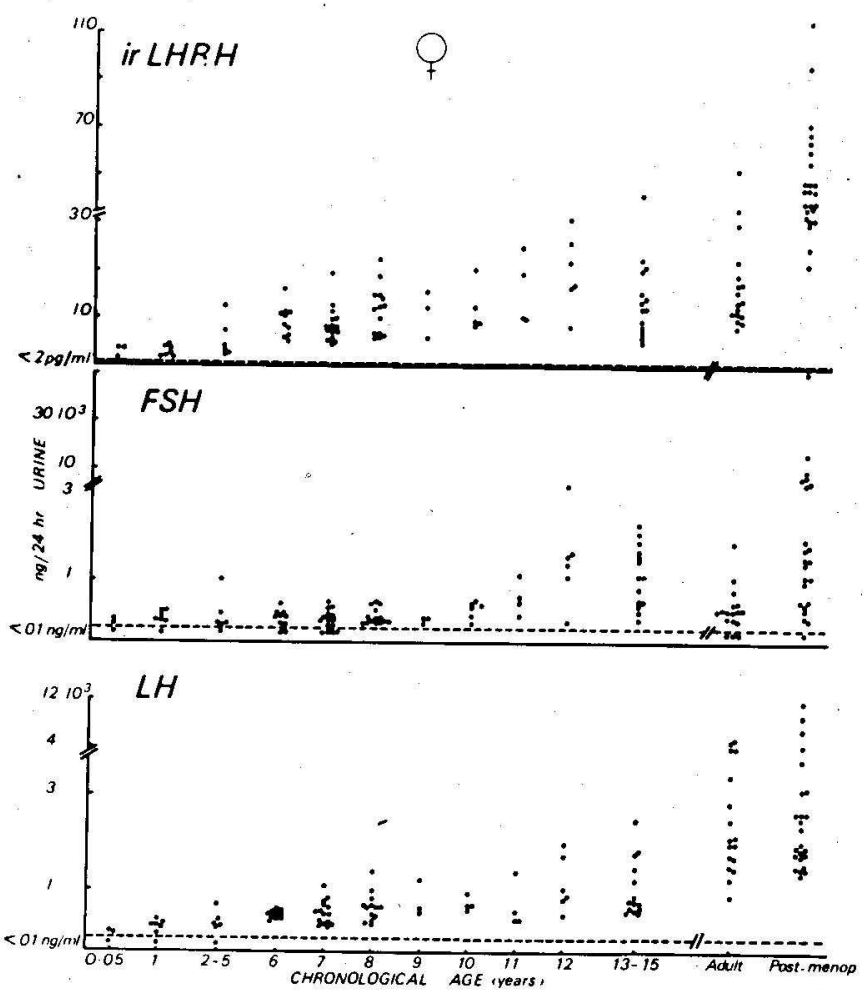

FIG. 6. Individual values of urinary IR LHRH, FSH, and LH (nanograms per $24 \mathrm{~h}$ ) were referred to the chronological ages of normal females. Values plotted under the dotted lines were below the limit of assay sensitivity. The youngest girl was aged 12 weeks.

In addition, the incubation of the decapeptide in urine changed its chromatographical mobility to that observed with the nonapeptide. However, this material retained its recognition sites by two antisera, suggesting an alteration of its chromatographical polarity but not its amino acid sequence.

The measurement of urinary IR LHRH could be an approach to an assessment of its rate of secretion by the hypothalamus. In fact, the measurement of $24-h$ urinary levels could be regarded as a means of integrating the pulsatile secretory pattern of this hormone in plasma (19) and avoiding the methodological problems introduced by the low circulating plasma levels and short halflife. In this study, the extraction and RIA of LHRH were applied to 24-h urine collections of normal subjects. Urinary IR LHRH was found to increase gradually in prepubertal boys and girls and markedly in postmenopausal women. The first observation is not in full agreement with results recently reported by Root et al. (6); in our study, urinary IR LHRH of the pubertal group (11-15 yr) did not appear different from the late prepubertal ages but was significantly higher than prepubertal children before $9 \mathrm{yr}$ of age. This prepubertal increase of IR LHRH excretion in urine could be an expression of changes occurring at the hypothalamic level and appeared earlier than the increase of gonadotropins release related to the onset of puberty. An increased LHRH production was previously assumed by Grumbach et al. (20) as the first event in the sequence of hypothalamopituitary mechanisms leading to puberty. An interesting point is the finding of higher values in girls than in boys of $6 \mathrm{yr}$, as the beginning of puberty is earlier in the former than in the latter. This requires further confirmation with study of more subjects and correlation with bone ages and pubertal stages.

The correlation between urinary IR LHRH and gonadotropins was calculated in several groups of subjects at different periods of life. In infants of both sexes, the low urinary LHRH values found were without significant correlation with urinary gonadotropins. This might suggest that the release of gonadotropins is mainly controlled at the pituitary level by adrenal and gonadal steroids during infancy. Nevertheless, a detailed study of neonates and infants would be required in order to confirm this hypothesis. The first few days of life are a peculiar period for hormone production and regulation and were not considered in this study. A significant positive correlation between urinary IR LHRH and both gonadotropins was observed in boys and girls during prepuberty. Furthermore, the prepubertal increase of urinary IR LHRH did not lead to a consequent increase of gonadotropin excretion before the age of puberty. Both observations suggest that during prepuberty the release of gonadotropins is related to LHRH stimulation but is controlled by a high sensitivity of the pituitary to the negative feedback action of steroids.

Finally, in pubertal boys, a significant positive correlation was observed. In contrast, no significant correlation was found in females from puberty to the menopause. Since the gonadotropin release of eugonadal and postmenopausal women has been shown to be modulated by gonadal steroids (21), the absence of correlation between IR LHRH and gonadotropins in urine enhances the role of these factors at the pituitary level in the gonadotropin regulation. Nevertheless, the finding of increased IR LHRH in urine of menopausal women suggests a direct feedback effect of gonadal steroids at the hypothalamic level. Further studies of urinary IR LHRH excretion after steroid administration could add to the comprehension of those mechanisms.

TABLE 2. Correlation between urinary IR LHRH and gonadotropins

\begin{tabular}{lccccc}
\hline \multirow{2}{*}{ Age groups } & \multicolumn{2}{c}{ Males } & & \multicolumn{2}{c}{ Females } \\
\cline { 2 - 3 } \cline { 5 - 6 } & LH & FSH & & LH & FSH \\
\hline Infants (0-18 months) & -0.21 & -0.12 & & 0.18 & 0.04 \\
Prepubertal (2-10 yr) & $0.53^{a}$ & $0.59^{a}$ & & $0.55^{a}$ & $0.34^{a}$ \\
Pubertal (11-15 yr) & $0.50^{a}$ & $0.48^{a}$ & & 0.20 & 0.15 \\
Adults & $0.54^{a}$ & 0.31 & & -0.02 & -0.25 \\
Postmenopausal & & & & -0.30 & -0.14 \\
\hline \multicolumn{2}{c}{${ }^{a} P<0.05$}
\end{tabular}

${ }^{a} P<0.05$. 


\section{Acknowledgments}

Standard LHRH and fragments were a generous gift of Dr. Sandow (Hoechst A.G.). Anti-LHRH serum R-42 was kindly provided by Drs. Nett and Niswender. We wish to thank Prof. S. L. Kaplan, Dr. R. J. Santen, and Dr. Chr. Ernould for their comments on this manuscript. We acknowledge Mrs. M. Beyer and I. Damseaux for drawing the illustrations.

\section{References}

1. Redding, T. W., A. J. Kastin, D. Gonzalez-Barcena, D. H. Coy, E. J. Coy, D. S. Salch, and A. V. Schally, The half-life, metabolism and excretion of tritiated luteinizing hormone-releasing hormone (LH-RH) in man, $J$ Clin Endocrinol Metab 37: 626, 1973.

2. Bolton, A. E., Radioimmunoassay of luteinizing hormone releasing hormone-like material in human urine, $J$ Endocrinol 63: 255, 1974.

3. Dupont, A., F. Labrie, G. Pelletier, R. Puviani, D. H. Coy, E. J. Coy, and A. V. Schally, Organ distribution of radioactivity and disappearance of radiaoctivity from plasma after administration of $\left[{ }^{3} \mathrm{H}\right]$ luteinizing hormone-releasing hormone to mice and rats, $\mathrm{Neu}$ roendocrinology 16: $65,1974$.

4. Jeffcoate, S. L., R. H. Greenwood, and D. T. Holland, Blood and urine clearance of luteinizing hormone releasing hormone in man measured by radioimmunoassay, $J$ Endocrinol 60: 305, 1974.

5. Jeffcoate, S. L., and D. T. Holland, Further studies on the nature of the immunoreactive luteinizing hormone-releasing hormone (LH-RH)-like peptide in human urine, Acta Endocrinol (Kbh) 78: $232,1975$.

6. Root, A. W., E. O. Reiter, and G. E. Duckett, Urinary excretion of immunoreactive gonadotropin-releasing hormone-like material in prepubertal and pubertal children, J Clin Endocrinol Metab 44: 909, 1977.

7. Copeland, K. C., M. L. Aubert, L. Paunier, and P. C. Sizonenko, Measurement of urinary LHRH, 11th Acta Endocrinologica Congress, 1977 (Abstract 70).

8. Bourguignon, J. P., and P. Franchimont, Urinary luteinizing hormone-releasing hormone (LH-RH)-like immunoreactivity and gonadotrophins during three normal reproductive cycles, Acta Endocrinol $(K b h)$ 86: 15, 1977.

9. Bourguignon, J. P., C. Dourcy, and P. Franchimont, Mise au point de l'extraction du LHRH dans les urines humaines: étude de l'extraction de l'hormone synthétique marquée, $C R$ Soc Biol (Paris) 170: 194, 1976.

10. Bourguignon, J. P., H. G. Burger, and P. Franchimont, Radioimmunoassay of serum luteinizing hormone-releasing hormone ( $\mathrm{LH}$ $\mathrm{RH}$ ) after intranasal administration and evaluation of the pituitary gonadotrophic response, Clin Endocrinol 3: 437, 1974.

11. Burger, H., and P. Franchimont, Studies on a radioimmunoassay for luteinizing hormone-releasing hormone (LH-RH), Horm Metab Res (Suppl) 5: 61, 1974.

12. Nett, T. M., A. M. Akbar, G. D. Niswender, M. T. Hedlund, and W. F. White, A radioimmunoassay for gonadotropin-releasing hormone (Gn-RH) in serum, J Clin Endocrinol Metab 36: 380, 1973.

13. Jonas, H. A., H. G. Burger, I. A. Cumming, J. K. Findlay, and D. M. De Kretser, Radioimmunoassay for luteinizing hormone-releasing hormone (LHRH): its application to the measurement of LHRH in ovine and human plasma, Endocrinology 96: 384, 1975.

14. Dalhen, H. G., K. H. Voigt, and H. P. G. Schneider, C- and Nterminal specific LH-releasing hormone (LRH) radioimmunoassay, Horm Metab Res 8: 61, 1976.

15. Franchimont, P., Radioimmunoassay of gonadotrophic hormones, In Margoulies, M. (ed.), Protein and Polypeptide Hormones, part 1, Amsterdam, Excerpta Medica, 1968, p. 99.

16. Reuter, A. M., J. C. Hendrick, and P. Franchimont, Mise au point d'un dosage radioimmunologique rapide des gonadotrophines, Ann Biol Clin (Paris) 31: 479, 1973.

17. Bourguignon, J. P., C. Leinartz-Dourcy, and P. Franchimont, Excretion urinaire du LHRH après injection intraveineuse chez le lapin et chez l'homme, $C R$ Soc Biol (Paris) 171: 464, 1977.

18. Mortimer, C. H., and H. G. Dobbie, Radioimmunoassay and chromatographic similarity of circulating endogenous gonadotropin releasing hormone and hypothalamic extracts in man, J Clin Endocrinol Metab 43: 882, 1976.

19. Seyler, L. E., Jr, and S. Reichlin, Episodic secretion of luteinizing hormone-releasing factor (LRF) in the human, $J$ Clin Endocrinol Metab 39: 471, 1974.

20. Grumbach, M. M., J. C. Roth, S. L. Kaplan, and R. P. Kelch, Hypothalamic-pituitary regulation of puberty in man: evidence and concepts derived from clinical research, In Grumbach, M. M., G. D. Grave, and F. E. Mayer (eds.), Control of the Onset of Puberty, New York, John Wiley and Sons, 1974, p. 115.

21. Nillius, S. J., Normal gonadotropin secretion in females, In Martini, L., and G. M. Besser (eds.), Clinical Neuroendocrinology, New York, Academic Press, 1977, p. 143. 